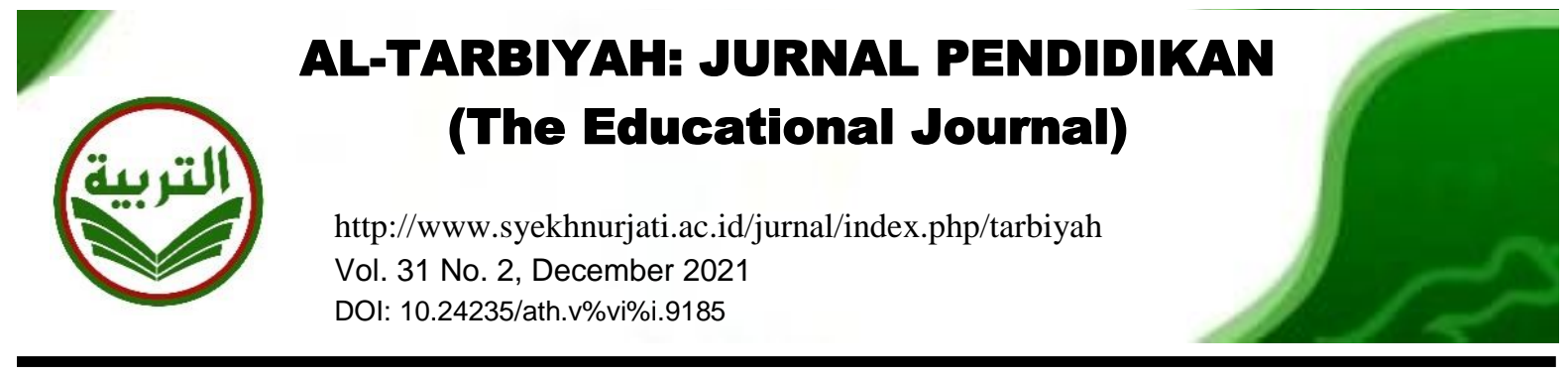

\title{
CONCEPT MAPPING: A WAY FOR INVESTIGATING STUDENTS' MATHEMATICAL UNDERSTANDING
}

\author{
Rizky Oktaviana Eko Putri \\ Pendidikan Matematika, Universitas Islam Majapahit \\ e-mail: rizky_putri@unim.ac.id
}

\begin{abstract}
Understanding the concept is one of the main goals in learning mathematics. Teachers as the main pillar in the implementation of learning can use various ways and methods to analyze the extent to which students understand the mathematical concepts being taught. One way that can be used by teachers to observe students' understanding is through a concept map. This study was a qualitative study with the purpose of describing students' understanding on mathematical concepts by using a concept map. The subjects of this study were three students who were selected based on differences in mathematical ability. Students were asked to develop a concept map according to their understanding of the material on mathematical functions. The results show that concept maps can show the level of students' understanding on mathematical concepts based on the number of relationships formed (map complexity). Students with high mathematical abilities can form a fairly complex concept map by showing the relationship of each given concept. On the other hand, students with low mathematical abilities have not been able to show the relationship between the concepts given yet.
\end{abstract}

Keywords: Understanding, Mathematical Concepts, Concept Maps

\section{INTRODUCTION}

The world of education is closely related to the learning process. The main purpose of this learning process is to make students understand the materials being taught. Mathematics is one of important knowledge in daily life. Therefore, understanding and learning mathematics will be very helpful in solving problems. Understanding is regarded as "to make (cognitive) connections" (Haylock, 1982). The more students can make connections between new knowledge and prior knowledge, the deeper their understanding will be. There are two kinds of learning, habit learning or rote learning and learning with understanding (Skemp, 1976). Rote learning tends to be temporary because information is stored in short-term memory, whereas learning with understanding relates to the storage of information in long-term memory. Learning with understanding has been recognized as the most important part in mathematics education (Jung, 2002). 
Understanding is divided into three types according to Skemp (1987). They include (1) instrumental understanding; (2) relational understanding, and (3) formal understanding. Instrumental understanding is defined as "rule without reason". Someone with this type of understanding will know the rules that are applied in mathematics without knowing the reasons why the rules occur. Relational understanding can be defined as "knowing what to do and why". Someone with relational understanding will be able to deduce the specific rules or procedures from a common mathematical relationship. Formal understanding is defined as the ability to connect symbols and notations with relevant mathematical ideas and incorporate those ideas into logical rationales.

The National Council of Teachers of Mathematics or NCTM (2000) lists understanding as an important factor in the learning process and one of the basic principles in learning. There are six principles in learning mathematics. Those principles are (1) Equity; (2) Curriculum; (3) Teaching; (4) Learning; (5) Assessment; and (6) Technology. The learning principle explains that "Students must learn mathematics with understanding, actively building new knowledge from experience and prior knowledge" (NCTM, 2000, p. 20). Thus, teachers should find effective ways to observe students' understanding.

Students' understanding of a concept can be assessed through various ways. One of them is through concept maps. Concept maps were developed by Novak and Gowin (1984) in the 1970s on the basis of meaningful learning theory proposed by
Ausubel. Concept maps are effective instruments for assessing conceptual understanding in education (Haiyue \& Wong, 2008). Baroody defines the concept map as a two-dimensional map using "nodes", that is used to present the concepts and lines labeled, to indicate a connection between the connected "nodes" (Haiyue \& Wong, 2008). Concept maps are used to present meaningful hierarchical relationships between concepts in a propositional form (Novak, 2010). The proposition is defined as two or more concepts connected by words in semantic units (meaningful). Some experts argue that the concept map analysis technique created by Novak was still focusing on scoring. This can make teachers skip important information related to students' conceptual understanding (Kimchin et al., 2000; Kastberg, 2002; Ruiz-Primo \& Shavelson, 1996; Liu \& Hinchey, 1996). Accordingly, qualitative descriptions of concept maps are needed to provide detailed information of students' understanding.

There are three main types of concept maps according to Kimchin, et al. (2000), such as Spoke, Chain, and Net. Spoke is a radial structure in which all the related aspects of the topic are linked directly to the core concept, but are not directly to each other. Chain is a linear sequence of understanding in which each concept is only linked to those immediately above and below. Though a logical sequence exists from beginning to end, the implied hierarchical nature of many of the links is not valid. Net is a highly integrated and hierarchical network demonstrating a deep understanding of the topics. 


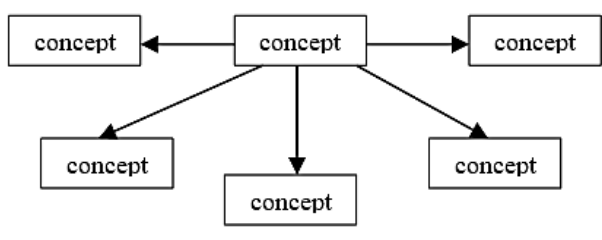

(a)

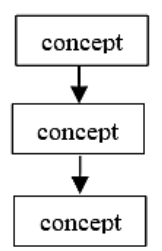

(b)

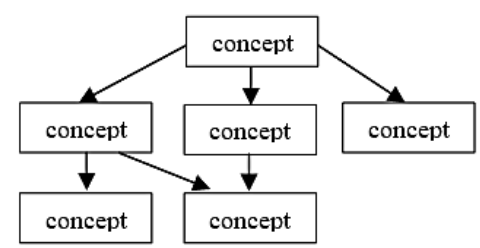

(c)

Figure 1. Main Types of Concept Map: (a) Spoke, (b) Chain, and (c) Net

Concept maps are effective media for assessing students' conceptual understanding (Haiyue \& Wong, 2008; Novak \& Cañas, 2010; Kimchin, et al., 2000; Brinkmann, 2003; Schmittau, 2004; Afamasaga-Fuata'I, 2007; Ritchhart, et al., 2009). Haiyue \& Wong (2008) stated in his research that concept maps are useful sources of information for assessing students' understanding of mathematical concepts. In addition, student's misconceptions can also be seen through concept maps that they created. Students' understanding of mathematical concepts is closely related to students' mathematical skills.

Mathematical ability in this research is divided into three categories, namely high; medium; and low mathematical skills. The grouping of students is based on the results of the students' mathematics test scores. Students' understanding is related to students' mathematical abilities (Borovik \& Gardiner, 2006). Therefore, it is necessary to have an appropriate instrument to see how well students understand a concept that has been studied, especially concepts in mathematics. Thus, the main problems of students in understanding a concept can be identified and the problems faced by any levels of students' mathematical skills can be overcome.

\section{RESEARCH METHOD}

The goal of this research was to describe students' understanding about mathematical concepts using concept maps. Qualitative method was used in data analyzing.

The participants of this research were three Junior High School students. Those three participants were chosen from 30 students by referring to the results of mathematical ability tests developed by researchers. The selection was based on the following criteria showed in Table 1.

Table 1. Mathematical Ability Category

\begin{tabular}{ccc}
\hline No. & Score & Mathematical Ability Category \\
\hline 1. & $85 \leq x \leq 100$ & High \\
2. & $75 \leq x<85$ & Intermediate \\
3. & $0 \leq x<75$ & Low \\
\hline
\end{tabular}

There were three mathematical ability categories. Then one person was chosen from each category. In this study, data were collected by giving students nodes, collections of mathematical concepts about functions that would be constructed as concept maps. Interviews were conducted to verify the data obtained. In addition, through interviews, new information that 
was not obtained when observing students create a concept map would be revealed.

Triangulation was conducted to check the credibility of the data. There are three kinds of triangulations, i.e. source, method and time triangulation. Time triangulation was used in this study. Researchers took data from the same participants but in different times. If the data obtained are consistent in the sense of having much in common from the first data (first concept mapping), then the data obtained are said to be valid. If the data obtained with triangulation have not been consistent, the process is repeated until the data obtained consistency with the last data taken. Then the data is said to be valid.

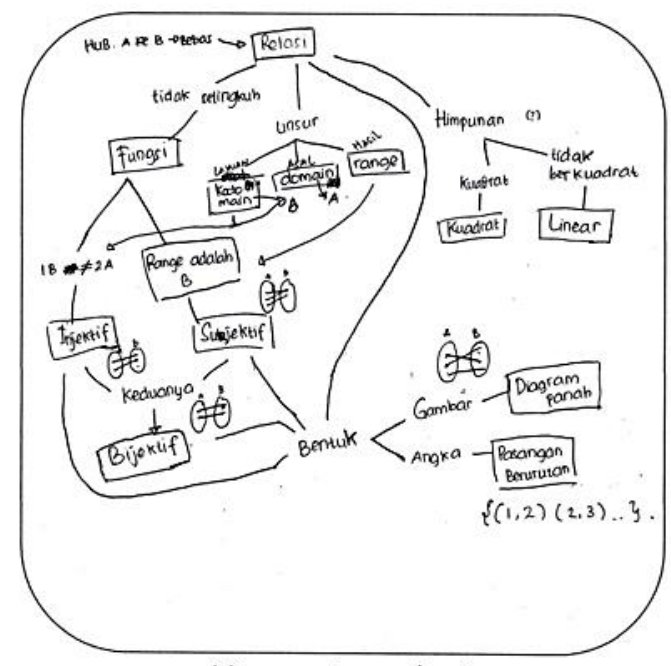

(a) concept mapping 1

\section{RESULT AND DISCUSSION}

Three criteria of concept maps were used in this study, including structural (complexity of the hierarchical structure of concepts), contents (nature of the contents or entries in the concept nodes), and propositions criteria (valid propositions) (Schmittau, 2004). The data collected by giving the three chosen students some concepts nodes. They were given enough time to construct concept maps using those nodes. The researcher provided 12 nodes for students to be constructed as concept maps. Here is the data analysis for the three students.

\section{Student 1: High Mathematical Ability}

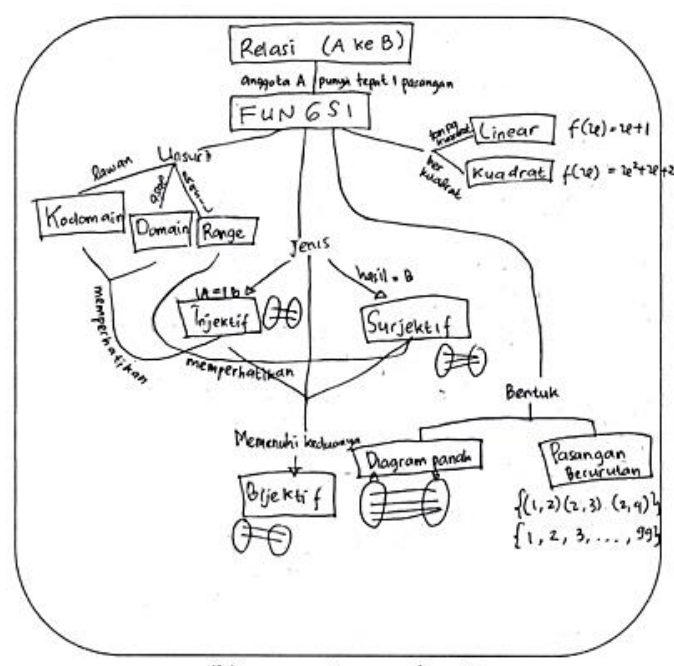

(b) concept mapping 2

Figure 2. Concept Maps by High Mathematical Ability Student

For structural criterion, concept maps composed by high mathematical ability student illustrates that the student was able to see the relationships between concepts. This can be seen from interconnected concepts and a valid hierarchy. The student was able to deduce the applicable relationship between the injective function and the subjective function with the domain, co-domain, and range through connections. For the content and proposition criteria, it can be seen that the student was capable of explaining the notion of any given concept but having difficulty to connect several concepts, such as algebraic (linear and quadratic) function concepts with domain, co-domain, and range. The use of inconsistent symbols to represent relationships between concepts 
leads to differences in the first and second points despite having the same intention.

\section{Student 2: Intermediate Mathematical Ability}

The student with intermediate mathematical ability composed several concepts with less precision in hierarchy, such as the arrangement of domain concepts, codomain and range. There was an invalid relationship in the concept map. That is the relationship between the concept of

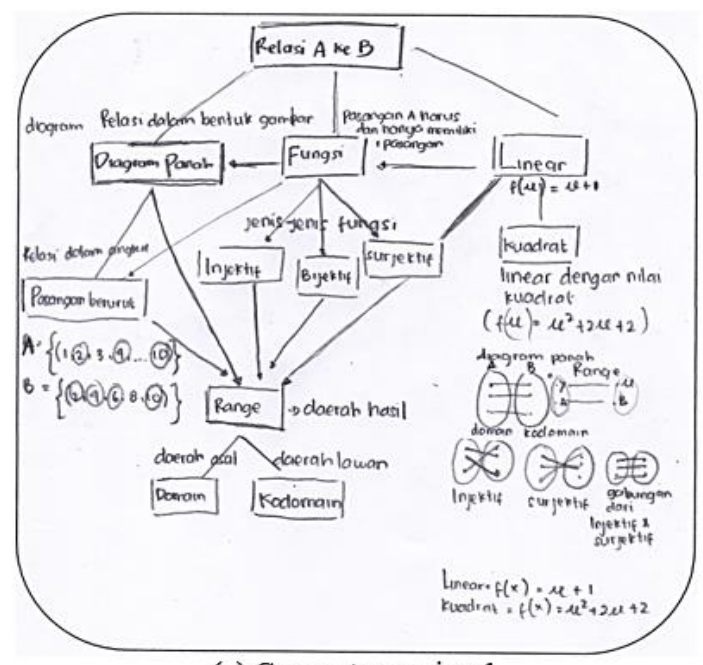

(a) Concept mapping 1 relations with linear and quadratic concepts. In addition, there were still concepts that had not been connected e.g. the concept of domain and co-domain with other concepts. For the content and proposition criteria, the student was able to explain the intent of all given concepts but still had difficulty in explaining the relationship for some concepts. The labels given to illustrate the relationships between concepts are still too general to reflect the specific relationship between concepts.

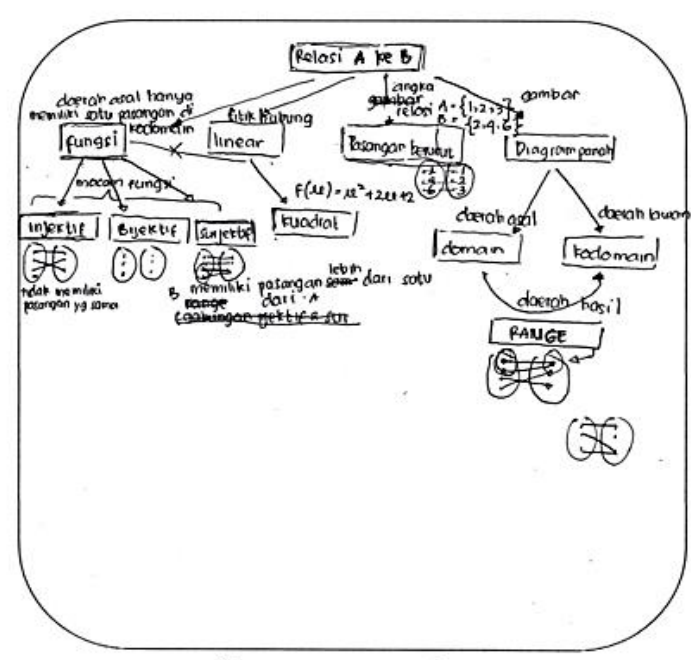

(b) Concept mapping 2

Figure 3. Concept Maps by Intermediate Mathematical Ability Student

\section{Student 3: Low Mathematical Ability}

The concept map structure composed by low mathematical ability student was very simple, involving only four concepts from the 12 concepts provided. Based on the concept and concept map structure expressed by this student during the interview, it can be concluded that the student still has low understanding about the function. It can be seen from the concept map that the student was not able to connect the concepts that have been been provided. For content and proposition, it is known that the student only uses a small portion of the concept that has been provided to construct concept maps. The interview results reveal that the student has low understanding of the function material. This student's understanding was only limited in distinguishing relation, function and the properties. In addition, the interview also shows that the student actually understand the concept of domain, co-domain and range but has not been able to disclose it specifically. 


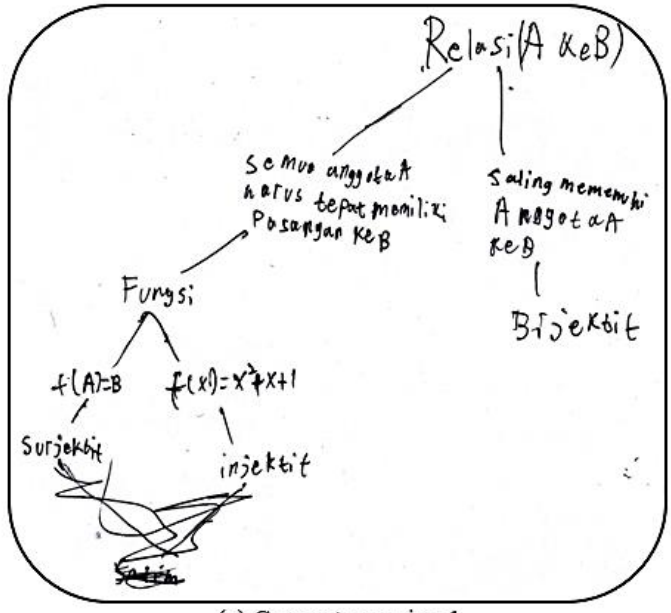

(a) Concept mapping 1

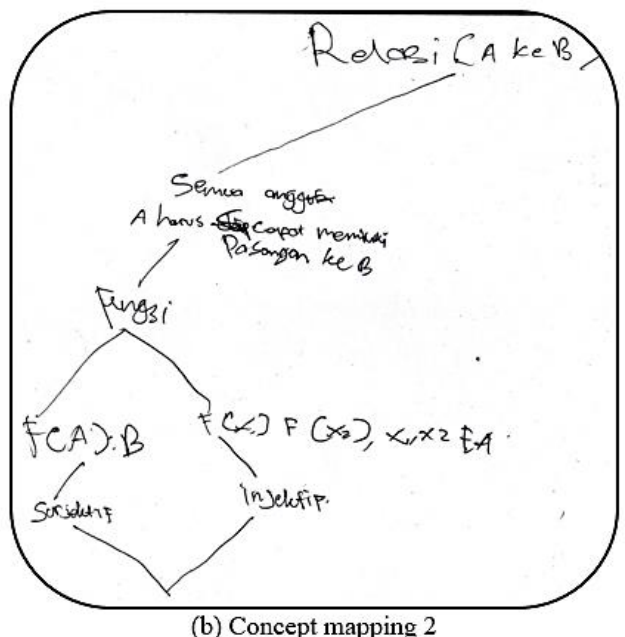

(b) Concept mapping 2

Figure 4. Concept Maps by Low Mathematical Ability Student

Broadly speaking the results of the study indicates that the complexity of concept maps is commensurate with the level of mathematical ability. The comparison of concept maps created by students from three different mathematical abilities can be seen in this table.

Table 2. Concept Maps Comparison

\begin{tabular}{|c|c|c|c|}
\hline \multirow{2}{*}{$\begin{array}{l}\text { Concept Map } \\
\text { Criteria }\end{array}$} & \multicolumn{3}{|c|}{ Mathematical Ability } \\
\hline & High & Intermediate & Low \\
\hline Structural & $\begin{array}{l}\text { - The student was able } \\
\text { to see the } \\
\text { relationships } \\
\text { between concepts. } \\
\text { - Concepts } \\
\text { interconnected } \\
\text { formed a valid } \\
\text { hierarchy. }\end{array}$ & $\begin{array}{l}\text { - The student composed } \\
\text { several concepts with less } \\
\text { precision in hierarchy. } \\
\text { - There was an invalid } \\
\text { relationship in the concept } \\
\text { map }\end{array}$ & $\begin{array}{l}\text { - The student composed a } \\
\text { very simple concept } \\
\text { map, involving only four } \\
\text { concepts from the } 12 \\
\text { concepts provided. } \\
\text { - The student was not able } \\
\text { to see the connection } \\
\text { between all concepts. }\end{array}$ \\
\hline Proposition & $\begin{array}{l}\text { The student was } \\
\text { capable of } \\
\text { explaining the notion } \\
\text { of any given concept } \\
\text { but still having } \\
\text { difficulty connecting } \\
\text { several concepts. }\end{array}$ & $\begin{array}{l}\text { The labels given to } \\
\text { illustrate the relationships } \\
\text { between concepts were } \\
\text { still too general to reflect } \\
\text { the specific relationship } \\
\text { between concepts }\end{array}$ & $\begin{array}{l}\text { - The student only use } \\
\text { four concepts. } \\
\text { - The student was not able } \\
\text { to give appropriate labels } \\
\text { to show the relationship } \\
\text { between concepts. }\end{array}$ \\
\hline Content & $\begin{array}{l}\text { There were still } \\
\text { inconsistent symbols } \\
\text { to represent } \\
\text { relationships } \\
\text { between concepts. }\end{array}$ & $\begin{array}{l}\text { The student was able to } \\
\text { explain the intent of all } \\
\text { given concepts, but still } \\
\text { had difficulty in } \\
\text { explaining the relationship } \\
\text { for some concepts. }\end{array}$ & $\begin{array}{l}\text { The student's } \\
\text { understanding was only } \\
\text { limited in distinguishing } \\
\text { relation and function and } \\
\text { the properties. }\end{array}$ \\
\hline
\end{tabular}


The degree of understanding is determined by the number and the strength of the connections. A mathematical idea, procedure, or fact is understood thoroughly if it is linked to existing network with stronger or more numerous connections (Stylianides \& Stylianides, 2007; Hiebert \& Carpenter, 1992). Subjects with high mathematical abilities constructed a more complex concept map compared to subjects with moderate and low math skills. The complexity of a concept map can be seen from points obtained from each criterion (Haiyue \& Wong, 2008).

In this study, it can be seen that the points obtained are directly proportional to the level of mathematical ability, in which subjects with high ability gain higher points than subjects with intermediate and low mathematical skills. Concept maps of subjects with high mathematical ability have a net-shaped structure which shows good understanding of a material. The subject was able to see the relationship between concepts (Kimchin, et al., 2000). The complexity of concept maps by highability subjects is supported also by providing examples and the use of appropriate links. Subjects with mathematical ability are making concept maps with a spike-shaped structure (Spoke) for some concepts, where all concepts are connected to a core concept. Thus, the relationships among concepts are not visible. On the other hand, subjects with low math skills makes a very simple concept map which involves only a small number of concepts from the overall concept provided.

Although the concept maps arranged by student with high mathematical abilities have a high complexity compared to the other two levels, there were some shortcomings in the concept maps. The placement of examples among concepts looks like a link but there are still some relationships between concepts that do not have links. This also happens in concept maps arranged by subjects with intermediate mathematical skills. This sample placement error could be caused by the lack of students' understanding about how to construct the correct concept map. This can be overcome by providing practices to arrange concept maps regularly because the quantity of practices is very influential in the preparation of a good concept map (Haiyue \& Wong, 2008). Concept maps are effective tools for seeing one's understanding of certain material (Haiyue \& Wong, 2008; Schmittau, 2004). In addition, concept maps could also assess students' misconceptions about a material.

\section{CONCLUSION}

Concept maps can be used as an effective tool to assess students' understanding of the concepts they have learned. This can be seen from the analysis of concept maps of students with different mathematical abilities. Of the three criteria assessed (content, proposition, structural), the student with high mathematical ability could create a complex concept map compared to the students with moderate and low mathematical skills.

Concept map practice is essential in daily learning activities. The longer the practice is given, the more adept the students will be at creating concept maps. Thus, students will provide additional information into the concept map that will make it more complex. 


\section{REFERENCES}

Afamasaga-Fuata'i,

K. (2007). Communicating understanding of undergraduate mathematics using concept maps. Jane Watson \& Kim Beswick, 133.

Borovik, A. and Gardiner, T. (2006). Mathematical Abilities and Mathematical Skills. England: Cambridge

Brinkmann, A. (2003). Graphical knowledge display-mind mapping and concept mapping as efficient tools in mathematics education. Mathematics Education Review, 16(4), 35-48.

Haylock, D.W. (1982). Understanding in Mathematics: Making Connections. Mathematics Teaching, 98, 54 - 56

Hiebert, J., \& Carpenter, T. P. (1992). Learning and teaching with understanding. Handbook of research on mathematics teaching and learning: A project of the National Council of Teachers of Mathematics, 65-97.

Jung, I. (2002). Student Representation and Understanding of Geometric Transformation with Technology Experience. Doctoral dissertation the University of Georgia.

Kastberg, S. E. (2002). Understanding mathematical concepts: The case of the logarithmic function (Doctoral dissertation, University of Georgia)

Liu, X., \& Hinchey, M. (1996). The internal consistency of a concept mapping scoring scheme and its effect on prediction validity. International Journal of Science Education, 18(8), 921-937.

NCTM. (2000). Principles and Standards for School Mathematics. www.nctm.org
Novak, J.D. (2000). Helping Students Learn How to Learn: A View from a Teacher-Researcher. New York: Cornell University

Novak, J. D., \& Cañas, A. J. (2010). The Theory Underlying Concept Maps and How to Construct Them. Florida Institute for Human and Machine Cognition: Pensacola, FL.

Novak, J.D. and Gowin, D.B. (1984). Learning How to Learn. London: Cambridge University Press

Ritchhart, R., Turner, T., \& Hadar, L. (2009). Uncovering students' thinking about thinking using concept maps. Metacognition and Learning, 4(2), 145-159.

Ruiz-Primo, M. A., \& Shavelson, R. J. (1996). Problems and issues in the use of concept maps in science assessment. Journal of research in science teaching, 33(6), 569-600.

Schmittau, J. (2004, September). Uses of concept mapping in teacher education in mathematics. In $A J$ Canãs, $J D$ Novak \& Gonázales (Eds), Concept Maps: Theory, Methodology, Technology. Proceedings of the First International Conference on Concept Mapping (pp. 571-578).

Skemp, R.R. (1976). Relational Understanding and Instrumental Understanding. Mathematics Teaching 77, $20-26$

Skemp, R.R. (1987). The Psychology of Learning Mathematics Expanded American Edition. New Jersey: Lawrence Erlbaum Assocites, Inc.

Stylianides, A. J., \& Stylianides, G. J. (2007). Learning mathematics with understanding: A critical consideration of the learning principle in the principles and standards for school mathematics. The Mathematics Enthusiast, 4(1), 103-114. 